\title{
Trends and burden of diabetes in pregnancy among Aboriginal and non-Aboriginal mothers in Western Australia, 1998-2015
}

\author{
Marwan Awad Ahmed ${ }^{1,2 *}$, Helen D. Bailey ${ }^{1}$, Gavin Pereira ${ }^{1,3,4}$, Scott W. White ${ }^{5,6}$, Kingsley Wong ${ }^{1,3}$ and \\ Carrington C. J. Shepherd ${ }^{1,7,8}$
}

\begin{abstract}
Background: Diabetes in pregnancy (DIP), which includes pre-gestational and gestational diabetes, is more prevalent among Aboriginal women. DIP and its adverse neonatal outcomes are associated with diabetes and cardiovascular disease in the offspring. This study investigated the impact of DIP on trends of large for gestational age (LGA) in Aboriginal and non-Aboriginal populations, and added to the limited evidence on temporal trends of DIP burden in these populations.
\end{abstract}

Methods: We conducted a retrospective cohort study that included all births in Western Australia between 1998 and 2015 using linked population health datasets. Time trends of age-standardised and crude rates of pre-gestational and gestational diabetes were estimated in Aboriginal and non-Aboriginal mothers. Mixed-effects multivariable logistic regression was used to estimate the association between DIP and population LGA trends over time.

Results: Over the study period, there were 526,319 births in Western Australia, of which 6.4\% were to Aboriginal mothers. The age-standardised annual rates of pre-gestational diabetes among Aboriginal mothers rose from $4.3 \%$ in 1998 to 5.4\% in 2015 and remained below 1\% in non-Aboriginal women. The comparable rates for gestational diabetes increased from 6.7 to $11.5 \%$ over the study period in Aboriginal women, and from 3.5 to $10.2 \%$ among nonAboriginal mothers. LGA rates in Aboriginal babies remained high with inconsistent and no improvement in pregnancies complicated by gestational diabetes and pre-gestational diabetes, respectively. Regression analyses showed that DIP explained a large part of the increasing LGA rates over time in Aboriginal babies.

Conclusions: There has been a substantial increase in the burden of pre-gestational diabetes (Aboriginal women) and gestational diabetes (Aboriginal and non-Aboriginal) in recent decades. DIP appears to substantially contribute to increasing trends in LGA among Aboriginal babies.

Keywords: Aboriginal, Torres Strait islanders, Indigenous, Diabetes in pregnancy, Pre-gestational diabetes, Gestational diabetes, Large for gestational age

*Correspondence: marwan.ahmed@telethonkids.org.au

${ }^{1}$ Telethon Kids Institute, University of Western Australia, P.O. Box 855, West Perth, Western Australia 6872, Australia

Full list of author information is available at the end of the article

\section{Background}

It is well-established that diabetes in pregnancy (DIP) poses substantial risks to the fetus/neonate, including high or low birth weight, preterm birth, congenital anomalies and perinatal death [1]. DIP, which includes pre-gestational diabetes mellitus (PGDM) and gestational diabetes mellitus (GDM), also has long-term implications 
on the offspring. Intrauterine hyperglycemia and its associated adverse neonatal outcomes (high or low birth weight) significantly increase the risk of diabetes and cardiovascular disease in adulthood [2,3].

The prevalence of DIP is disproportionately high in Indigenous populations worldwide [4]. Among Australian Aboriginal and Torres Strait Islander (the First Nations Peoples of Australia; the term 'Aboriginal' is respectfully used hereafter-see Terminology in the Methods section for further details) mothers, DIP is more prevalent and the rates of type 2 diabetes mellitus (T2DM) in pregnancy may be ten times higher compared with nonAboriginal women [5]. The current PGDM rates among Aboriginal women in the Northern Territory of Australia are among the highest in the world [6]. The risk of GDM is 1.5 times higher in Aboriginal mothers [5]. The burden of DIP extends to neonates, as babies born to Aboriginal mothers with diabetes are at higher risk of adverse outcomes [7].

DIP is believed to add, directly or indirectly, to the burden of diabetes in Indigenous populations. Both DIP and high birth weight (HBW) exert a differential impact on the future risk of diabetes in Indigenous compared with non-Indigenous people $[8,9]$. Osgood et al. reported that intrauterine exposure to GDM is a major contributor to the intergenerational cycle that leads to the epidemic of type 2 diabetes (T2DM) among Canadian First Nations populations [8]. They concluded that GDM may be responsible for 19 to $30 \%$ of T2DM cases among Indigenous people, compared with $6 \%$ of cases in non-Indigenous individuals [8]. Indigenous Canadian women who had a HBW had substantially heightened risk of future T2DM and GDM when compared with their non-Indigenous counterparts [9].

The increasing rate of DIP has been a global trend [10-12]. In Australia, there is limited evidence on the change in the burden of DIP overtime among Aboriginal mothers. There is also scarcity of evidence about the temporal contribution of DIP to population-wide adverse neonatal outcomes and the possible long-term effect of DIP on Aboriginal offspring. A recent study from Australia's Northern Territory revealed that, over 30 years, the prevalence of PGDM increased ten-fold among Aboriginal mothers [6]. The study also found that DIP largely explained the increasing rates of LGA among Aboriginal women over three decades [6]. Evidence from other culturally distinct Aboriginal populations in other Australian states is lacking.

Studies incorporating the dimension of time provide a better understanding of the burden of DIP and its adverse perinatal outcomes on the intergenerational and long-term risk of chronic disease in the Aboriginal population. The established link between the disproportionate burden of cardiometabolic disease among Aboriginal people and their rapid shift toward a more sedentary lifestyle and less healthy diet $[13,14]$ adds to the importance of temporal shifts in studying such disparities. Investigating the interaction of DIP and its complications with time, besides describing the patterns of DIP-related inequalities, can shed light on possible distal drivers of health disparities between Aboriginal and non-Aboriginal people.

This study aims to compare the time trends of the burden of DIP in Aboriginal and non-Aboriginal populations, and to investigate whether, and to what extent, this burden impacts on trends of large for gestational age (LGA, as a measure of accelerated fetal growth that takes sex and gestational age into account) births in these populations.

\section{Methods}

\section{Study design and data sources}

This retrospective cohort study used population health datasets linked by the Data Linkage Branch (DLB) of the Western Australia Government Department of Health. DLB uses probabilistic matching methods to link datasets and provides researchers with de-identified data via secure data transfer methods [15] . Datasets linked include the Midwives Notification System (MNS), Hospital Morbidity Database Collection (HMDC), Births Registrations and Death Registrations. MNS, our primary data source contains details on the circumstances of all births occurring at $\geq 20$ weeks' gestation or birth weight of $400 \mathrm{~g}$ or more in Western Australia. HMDC includes information about inpatient episodes in all Western Australian private and public hospitals.

\section{Study population}

The study included all births at $\geq 20$ weeks' gestation occurring in WA between 1st January 1998 and 31st December 2015. A multiple pregnancy was counted once when calculating DIP rates. Multiple births $(n=15,558)$ were excluded from other analyses. Records missing GDM $(n=1912,0.4 \%)$ and PGDM $(n=2056,0.4 \%)$ were excluded from descriptive analyses. Multivariable analyses of LGA trends excluded records with missing gestational age $(n=2177,0.4 \%)$ and birth weight $(n=103$, $<0.1 \%)$. While remoteness and socioeconomic status were missing in $8232(1.6 \%)$ and 21,443 (4.1\%) records, respectively, the percentage of missing values for all other variables was below $0.5 \%$.

\section{Terminology}

The term 'Aboriginal' is respectfully used throughout this paper to refer to the First Nations peoples of the Australian continent-Aboriginal and Torres Strait Islander 
peoples. The term is used for the purpose of brevity and in preference to 'Indigenous'. While 'Aboriginal' is often the preferred term in Western Australian settings (and is a more specific term than 'Indigenous'), we recognise that it is a generic term that excludes any description of language group or Country and that it is not the preferred term among all Aboriginal and Torres Strait Islander peoples.

\section{Data management \\ Exposure}

We used the Indigenous status flag introduced by the Western Australian Data Linkage Branch in 2014 to support a more complete and consistent identification of Aboriginal peoples in administrative data. This flag is created from a number of Western Australian core datasets using an algorithm created by the 'Getting our Story Right' project [16]. The project used a multi-stage median approach to generate a single Aboriginal status for each individual. PGDM was ascertained from the MNS and HMDC as a principal or additional diagnosis using the ICD-9-AM code 250 and ICD-10-AM codes E10-11, E13-14 and O24.0-24.3. Births of the same mother were linked within the MNS by the unique maternal identifier, allowing us to ascertain PGDM in earlier pregnancies. GDM was ascertained from the MNS and from HMDC as a principal or additional diagnosis using the relevant ICD codes (ICD9-AM code 648.8 and ICD-10-AM codes O24.4, O24.9).

\section{Outcomes and covariates}

Using Australian sex- and gestational age-specific birth weight percentiles [17], LGA was defined as birth weight $>90$ th percentile and SGA as birth weight $<10$ th percentile. Perinatal death was defined as stillbirth (fetal death at gestational age $\geq 20$ weeks or with $\geq 400 \mathrm{~g}$ birth weight) or neonatal death (death during the first 28 days of life). Preterm birth was defined as birth before 37 weeks' gestation. Based on the mother's residence, remoteness was classified into two categories (Remote and Very remote residence, or other) according to the Accessibility/Remoteness Index of Australia (ARIA) [18]. The values of the area-based Index of Relative Socioeconomic Disadvantage of the mother's residence at the birth was derived from the Census closest to the birth year and categorised into tertiles [19].

\section{Statistical analysis}

Characteristics of mothers with PGDM and GDM, stratified by Aboriginal status and six-year birth periods (1998-2003, 2004-2009 and 2010-2015), were described using counts and proportions. $\mathrm{P}$ trend was used to assess the statistical significance of linear trends in neonatal outcomes and maternal characteristics over the three periods. $\mathrm{P}$ trend relies on calculating a chi-square statistic for the linear trend (regression) of the proportion of the characteristic (as the outcome variable) on the time periods (as the explanatory variable) [20,21].

We calculated age-standardised rates for PGDM and GDM to account for the vastly different age profile of Aboriginal and non-Aboriginal mothers. Direct agestandardisation was performed using all mothers who gave birth in WA during the study period as the standard population.

Mixed-effects multivariable logistic regression models, with a random intercept for mother to account for the clustering effect from births to the same mother, were used to examine the contribution of DIP to the trends of LGA in Aboriginal and non-Aboriginal populations by estimating odds ratios (OR) and 95\% confidence intervals (CIs). The effects of adding PGDM, GDM and then both types of diabetes to an adjusted model that had LGA as the dependent variable and year (year of birth divided by 10 , in a continuous form, so that the change in OR can be interpreted as change per decade) as the independent variable were studied. To assess the assumption of linearity between log odds LGA and year, we applied locally weighted regression (lowess in Stata). Factors known to be associated with birth weight were initially considered for inclusion as covariates. We then excluded variables not associated with the primary independent variable of interest (year of birth) from the models. The covariates included in the models were maternal age (continuous), remoteness (binary), parity group (categorical: 0, 1, 2 and 3 or more), and smoking during pregnancy (binary). All analyses were conducted using Stata version 16 (StataCorp. 2019).

\section{Results}

There were 526,319 births to 299,158 mothers in Western Australia between 1998 and 2015. About 6.4\% of births $(n=33,696)$ were to Aboriginal mothers. There were distinct differences in most demographic and other characteristics by Aboriginal status, in both pregnancies complicated by DIP (Tables 1 and 2) and all pregnancies (Additional file 1: Table S1). Notably, Aboriginal mothers were younger, had a higher parity, and were more likely to live in a low SES or remote/very remote area, and smoke during pregnancy.

The overall age-standardised prevalence of PGDM was 4.6\% (95\% CI: 4.3, 4.9) in Aboriginal women and 0.7\% (95\% CI: 0.68, 0.72) among their non-Aboriginal counterparts. The age-standardised prevalence of GDM was $7.9 \%$ (95\% CI: 7.6, 8.3) and 5.8\% (95\% CI: 5.7, 5.9) in Aboriginal and non-Aboriginal mothers, respectively.

In pregnancies complicated by PGDM (Table 1), LGA rates among births to Aboriginal women remained stable 
Table 1 Maternal and neonatal characteristics of Aboriginal and non-Aboriginal singleton pregnancies complicated by pregestational diabetes, 1998-2015

\begin{tabular}{|c|c|c|c|c|c|c|c|c|}
\hline \multirow[t]{2}{*}{ Characteristic } & \multicolumn{4}{|l|}{ Aboriginal Mothers } & \multicolumn{4}{|c|}{ Non-Aboriginal mothers } \\
\hline & 1998 to $2003(n=266)$ & $\begin{array}{l}2004 \text { to } \\
2009 \\
(n=293)\end{array}$ & $\begin{array}{l}2010 \text { to } \\
2015 \\
(n=354)\end{array}$ & P trend & $\begin{array}{l}1998 \text { to } \\
2003 \\
(n=730)\end{array}$ & $\begin{array}{l}2004 \text { to } \\
2009 \\
(n=1096)\end{array}$ & $\begin{array}{l}2010 \text { to } \\
2015 \\
(n=1546)\end{array}$ & P trend \\
\hline \multicolumn{9}{|l|}{ Maternal Characteristics } \\
\hline \multicolumn{9}{|l|}{ Maternal age (years) } \\
\hline 25 or below & $75(28.2)$ & $66(22.5)$ & $71(20.1)$ & 0.019 & $146(20.0)$ & $154(14.1)$ & $194(12.5)$ & $<0.001$ \\
\hline$>25$ to 35 & $138(51.9)$ & $152(51.9)$ & $215(60.7)$ & 0.021 & $443(60.7)$ & $681(62.1)$ & $956(61.8)$ & 0.663 \\
\hline above 35 & $53(19.9)$ & $75(25.6)$ & $68(19.2)$ & 0.702 & $141(19.3)$ & $261(23.8)$ & $396(25.6)$ & 0.001 \\
\hline Mean $(S D)^{a}$ & $29.6(6.4)$ & $30.8(6.3)$ & $30.6(6.1)$ & 0.096 & $30.4(5.6)$ & $31.6(5.4)$ & $31.8(5.3)$ & $<0.001$ \\
\hline \multicolumn{9}{|l|}{ Parity group } \\
\hline 0 & $36(13.5)$ & $36(12.3)$ & $57(16.1)$ & 0.320 & $248(34.0)$ & $334(30.5)$ & $524(34.0)$ & 0.671 \\
\hline 1 & $46(17.3)$ & $43(14.7)$ & $72(20.3)$ & 0.266 & $260(35.6)$ & $430(39.2)$ & $542(35.1)$ & 0.486 \\
\hline 2 & $56(21.1)$ & $47(16.0)$ & $70(19.8)$ & 0.783 & $145(19.9)$ & $198(18.1)$ & $282(18.3)$ & 0.435 \\
\hline 3 plus & $128(48.1)$ & $167(57.0)$ & $155(43.8)$ & 0.186 & $77(10.5)$ & $134(12.2)$ & $195(12.6)$ & 0.177 \\
\hline Caesarean delivery & $125(47.0)$ & $171(58.4)$ & $216(61.0)$ & 0.001 & $397(54.5)$ & $672(61.3)$ & $890(58.0)$ & 0.295 \\
\hline Smoking during pregnancy & $119(44.7)$ & $153(52.2)$ & $186(52.5)$ & 0.065 & $151(20.7)$ & $161(14.7)$ & $166(10.8)$ & $<0.001$ \\
\hline \multicolumn{9}{|l|}{ SES tertiles } \\
\hline 1st (most disadvantaged) & $196(85.2)$ & $214(81.4)$ & $265(82.0)$ & 0.368 & $279(39.9)$ & $385(36.2)$ & $544(36.4)$ & 0.167 \\
\hline 2nd & $<35(<15.2)^{b}$ & $39(14.8)$ & $40(12.4)$ & 0.760 & $233(33.3)$ & $375(35.2)$ & $522(34.9)$ & 0.536 \\
\hline 3rd (least disadvantaged) & $<10(<4.3)^{b}$ & $10(3.8)$ & $18(5.6)$ & 0.022 & $187(26.8)$ & $304(28.6)$ & $428(28.6)$ & 0.407 \\
\hline $\begin{array}{l}\text { Remote or very remote } \\
\text { residence }\end{array}$ & $155(63.3)$ & $178(62.5)$ & $213(60.7)$ & 0.512 & $100(13.9)$ & $109(10.1)$ & $70(4.6)$ & $<0.001$ \\
\hline Preterm birth & $82(30.9)$ & $107(36.5)$ & $128(36.3)$ & 0.191 & $192(26.3)$ & $289(26.4)$ & $391(25.5)$ & 0.617 \\
\hline Preeclampsia & $50(18.8)$ & $28(9.6)$ & $27(7.6)$ & $<0.001$ & $131(18.0)$ & $73(6.7)$ & $106(6.9)$ & $<0.001$ \\
\hline \multicolumn{9}{|l|}{ Neonatal Characteristics } \\
\hline Perinatal death & $14(5.3)$ & $11(3.8)$ & $15(4.2)$ & 0.573 & $15(2.1)$ & $15(1.4)$ & $16(1.0)$ & 0.055 \\
\hline Female sex & $124(46.6)$ & $148(50.5)$ & $175(49.4)$ & 0.522 & $356(48.8)$ & $532(48.5)$ & $751(48.6)$ & 0.943 \\
\hline LGA & $89(33.6)$ & $100(34.1)$ & $116(32.9)$ & 0.833 & $280(38.4)$ & $423(38.6)$ & $502(32.7)$ & 0.002 \\
\hline SGA & $33(12.5)$ & $26(8.9)$ & $29(8.2)$ & 0.087 & $30(4.1)$ & $46(4.2)$ & $71(4.6)$ & 0.533 \\
\hline
\end{tabular}

Data represented as numbers (percentages)

LGA large for gestational age, SD standard deviation, SES socio-economic status, SGA small for gestational age

${ }^{a}$ The over time trends of maternal age (as a continuous variable) were assessed by simple linear regression

${ }^{b}$ To maintain confidentiality, the numbers (percentages) are not shown for small cells. Numbers in the second least prevalent groups are also not shown to prevent calculating numbers in small cells

over time (approximately one-third of these births) and decreased considerably in non-Aboriginal births (from 38.4 to $32.7 \%$ ). Smoking rates among Aboriginal mothers with PGDM increased by about eight percentage points, to $52.5 \%$ by $2010-15$. For non-Aboriginal mothers, on the other hand, there was a consistent drop in smoking rates over the study period (from 20.7 to $10.8 \%$ ). The rates of preeclampsia decreased with time in both Aboriginal and non-Aboriginal mothers.

In GDM pregnancies (Table 2), there was a decrease in LGA rates among births to Aboriginal and non-Aboriginal mothers over the three time periods $(29.7,21.9$ and $21.1 \%$ in Aboriginal and 19.2, 17.1, 13.3\% in nonAboriginal babies-in 1998-2003, 2004-09 and 2010-15, respectively). Smoking rates remained high (around 40\%) in Aboriginal pregnancies complicated by GDM with no marked improvement over time. In contrast, there was a consistent (and substantial) decrease in smoking rates among non-Aboriginal mothers, to $7.1 \%$ in $2010-15$. As with PGDM, preeclampsia rates decreased in Aboriginal and non-Aboriginal pregnancies complicated by GDM.

\section{Trends in pre-gestational diabetes}

There was both a substantially higher prevalence and more rapid rates of change in PGDM over time among Aboriginal women (Fig. 1 and Additional file 2: Fig. S1). Between 1998 and 2015, the age-standardised prevalence rates of PGDM grew from $4.3 \%$ (95\% CI: $2.7,5.9$ ) to $5.4 \%$ 
Table 2 Maternal and neonatal characteristics of Aboriginal and non-Aboriginal singleton pregnancies complicated by gestational diabetes, 1998-2015

\begin{tabular}{|c|c|c|c|c|c|c|c|c|}
\hline \multirow[t]{2}{*}{ Characteristic } & \multicolumn{4}{|c|}{ Aboriginal Mothers } & \multicolumn{4}{|c|}{ Non-Aboriginal mothers } \\
\hline & $\begin{array}{l}1998 \text { to } 2003 \\
(n=404)\end{array}$ & $\begin{array}{l}2004 \text { to } 2009 \\
(n=539)\end{array}$ & $\begin{array}{l}2010 \text { to } \\
2015 \\
(n=917)\end{array}$ & P trend & $\begin{array}{l}1998 \text { to } \\
2003 \\
(n=5088)\end{array}$ & $\begin{array}{l}2004 \text { to } \\
2009 \\
(n=7362)\end{array}$ & $\begin{array}{l}2010 \text { to } 2015 \\
(n=15,447)\end{array}$ & Ptrend \\
\hline \multicolumn{9}{|c|}{ Maternal Characteristics } \\
\hline \multicolumn{9}{|c|}{ Maternal age (years) } \\
\hline 25 or below & $140(34.7)$ & $192(35.6)$ & $356(38.8)$ & 0.114 & $590(11.6)$ & 855 (11.6) & $1657(10.7)$ & 0.037 \\
\hline$>25$ to 35 & $210(52.0)$ & $274(50.8)$ & $425(46.3)$ & 0.038 & $3249(63.9)$ & $4484(60.9)$ & $9896(64.1)$ & 0.106 \\
\hline above 35 & $54(13.4)$ & $73(13.5)$ & $136(14.8)$ & 0.429 & $1249(24.5)$ & $2023(27.5)$ & $3894(25.2)$ & 0.777 \\
\hline Mean $(S D)^{\mathrm{a}}$ & $28.2(6.2)$ & $28.1(6.2)$ & $28.1(6.3)$ & 0.609 & $31.7(5.3)$ & $32.1(5.3)$ & $31.9(5.2)$ & 0.145 \\
\hline \multicolumn{9}{|l|}{ Parity group } \\
\hline 0 & $70(17.3)$ & $98(18.2)$ & $238(26.0)$ & $<0.001$ & $1938(38.1)$ & $3098(42.1)$ & $6814(44.3)$ & $<0.001$ \\
\hline 1 & $81(20.0)$ & $108(20.0)$ & $208(22.7)$ & 0.210 & $1731(34.0)$ & $2374(32.2)$ & $5056(32.9)$ & 0.314 \\
\hline 2 & $76(18.8)$ & $96(17.8)$ & $163(17.8)$ & 0.690 & $856(16.8)$ & $1099(14.9)$ & $2179(14.2)$ & $<0.001$ \\
\hline 3 plus & $177(43.8)$ & $237(44.0)$ & $307(33.5)$ & $<0.001$ & $563(11.1)$ & $791(10.7)$ & $1322(8.6)$ & $<0.001$ \\
\hline Caesarean delivery & $141(34.9)$ & $188(34.9)$ & $356(38.9)$ & 0.108 & $1882(37.0)$ & 3161 (42.9) & $6545(42.7)$ & $<0.001$ \\
\hline $\begin{array}{l}\text { Smoking during } \\
\text { pregnancy }\end{array}$ & $166(41.1)$ & $208(38.6)$ & $373(40.8)$ & 0.926 & $814(16.0)$ & $818(11.1)$ & $1084(7.1)$ & $<0.001$ \\
\hline \multicolumn{9}{|l|}{ SES tertiles } \\
\hline $\begin{array}{l}\text { 1st (most disad- } \\
\text { vantaged) }\end{array}$ & $259(73.0)$ & $368(75.4)$ & $627(72.0)$ & 0.512 & $1709(35.1)$ & $2498(35.0)$ & 5357 (35.6) & 0.385 \\
\hline 2nd & $77(21.7)$ & 95 (19.5) & $188(21.6)$ & 0.844 & $1692(34.8)$ & $2383(33.4)$ & $5173(34.4)$ & 0.941 \\
\hline $\begin{array}{l}\text { 3rd (least disad- } \\
\text { vantaged) }\end{array}$ & $19(5.4)$ & $25(5.1)$ & $56(6.4)$ & 0.369 & $1465(30.1)$ & 2257 (31.6) & 4498 (29.9) & 0.328 \\
\hline $\begin{array}{l}\text { Remote or very } \\
\text { remote residence }\end{array}$ & $204(54.3)$ & $249(47.8)$ & $360(39.4)$ & $<0.001$ & $428(8.6)$ & $601(8.3)$ & $557(3.6)$ & $<0.001$ \\
\hline Preterm birth & $51(12.6)$ & $69(12.8)$ & $133(14.5)$ & 0.292 & $464(9.1)$ & 727 (9.9) & $1454(9.5)$ & 0.687 \\
\hline Preeclampsia & $42(10.4)$ & $37(6.9)$ & $35(3.8)$ & $<0.001$ & $433(8.5)$ & $317(4.3)$ & $384(2.5)$ & $<0.001$ \\
\hline \multicolumn{9}{|c|}{ Neonatal Characteristics } \\
\hline Perinatal death & $<10(<2.5)^{\mathrm{b}}$ & $<10(<1.9)^{\mathrm{b}}$ & $11(1.2)$ & 0.432 & $27(0.5)$ & $33(0.4)$ & $40(0.3)$ & 0.002 \\
\hline Female sex & $204(50.5)$ & $251(46.6)$ & $418(45.6)$ & 0.118 & $2418(47.5)$ & $3468(47.1)$ & $7463(48.3)$ & 0.172 \\
\hline LGA & $120(29.7)$ & $118(21.9)$ & $193(21.1)$ & 0.002 & $978(19.2)$ & $1259(17.1)$ & $2029(13.3)$ & $<0.001$ \\
\hline SGA & $32(7.9)$ & $42(7.8)$ & $65(7.1)$ & 0.563 & $310(6.1)$ & $507(6.9)$ & $1277(8.3)$ & $<0.001$ \\
\hline
\end{tabular}

Data represented as numbers (percentages)

LGA large for gestational age, SD standard deviation, SES socio-economic status, SGA small for gestational age

${ }^{a}$ The over time trends of maternal age (as a continuous variable) were assessed by simple linear regression

${ }^{b}$ To maintain confidentiality, the numbers (percentages) are not shown for small cells

(95\% CI: 4.1, 6.7) (Fig. 1) and the crude rates increased from $2.3 \%$ (95\% CI: $1.7,3.1$ ) to $3.8 \%$ (95\% CI: 3.1, 4.8) (Additional file 2: Fig. S1) among Aboriginal mothers. In non-Aboriginal women, age-standardised and crude annual rates of PGDM were similar, and increased from $0.6 \%$ (95\% CI: $0.5,0.7)$ in 1998 to $0.9 \%$ (95\% CI: $0.8,1.0)$ in 2015.

\section{Trends in gestational diabetes}

The age-standardised rates of GDM were consistently higher in Aboriginal women during the study period
(Fig. 2), although the trends over time in both standardised and crude rates (Additional file 3: Fig. S2) were comparable. Among Aboriginal mothers, the agestandardised rates of GDM increased from 6.7\% (95\% CI: $4.8,8.5)$ to $11.5 \%$ (95\% CI: 9.7 to 13.3$)$ and the crude rates increased from $4.6 \%$ (95\% CI: 3.7, 5.7) to $9.1 \%$ (95\% CI: 7.9, 10.4) between 1998 and 2015. Among non-Aboriginal mothers, the age-standardised rates of GDM increased from $3.5 \%$ (95\% CI: $3.3,3.8$ ) to $10.2 \%$ (95\% CI: 9.9, 10.6) and the crude rates increased from $3.4 \%$ (95\% CI: $3.2,3.7$ ) to $10.6 \%$ (95\% CI: $10.3,11.0)$ over this period. 


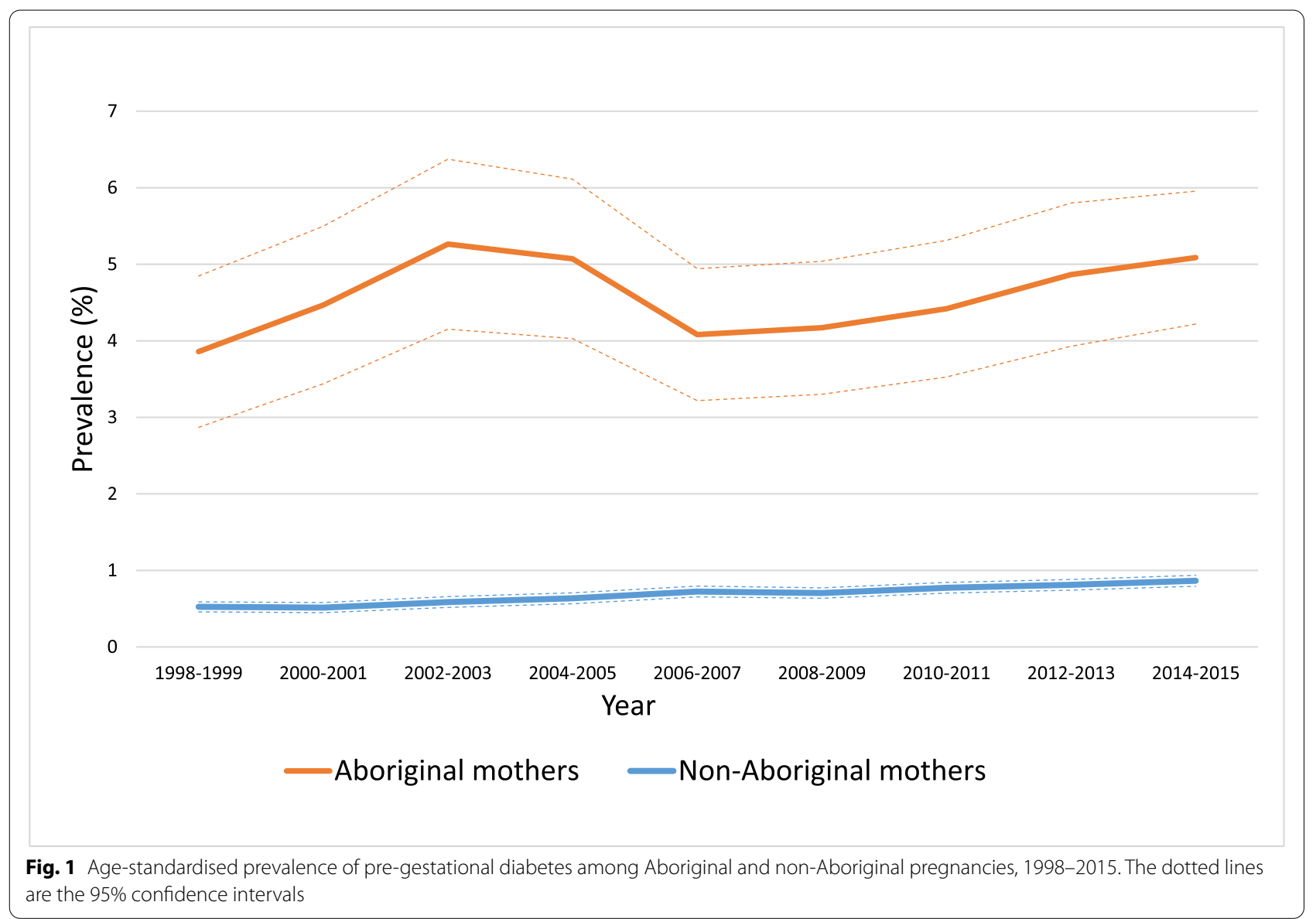

\section{Impact of diabetes in pregnancy on LGA trends in population}

Our initial mixed-effects multivariable model estimated a $16 \%$ increase per decade in the odds of LGA among births to Aboriginal women $(\mathrm{OR}=1.16,95 \% \mathrm{CI}$ : 1.04 , 1.29) after adjusting for maternal age, parity, remoteness and smoking during pregnancy, as well as for clustering by mother (Table 3 ). The elevated odds was attenuated to $10 \%$ by further adjustment for GDM (OR $=1.10$, $95 \%$ CI: $0.99,1.23)$ and to $14 \%$ by accounting separately for PGDM $(\mathrm{OR}=1.14,95 \% \mathrm{CI}: 1.02,1.26)$. Simultaneous adjustment for both GDM and PGDM resulted in a $7 \%$ increase per decade $(\mathrm{OR}=1.07,95 \% \mathrm{CI}$ : 0.97 to 1.19). Among non-Aboriginal mothers, the odds of LGA per decade decreased by $6 \%(\mathrm{OR}=0.94,95 \% \mathrm{CI}: 0.92$, 0.97 ) after adjusting for the same variables in the initial model above. The magnitude of the decrease was $7 \%$ $(\mathrm{OR}=0.93,95 \% \mathrm{CI}: 0.91,0.95)$ and $6 \%(\mathrm{OR}=0.94,95 \%$ CI: 0.91, 0.96) after accounting for GDM and PGDM, respectively. Compared to the initial model, adjusting for both GDM and PGDM reduced LGA odds by two percentage points and resulted in $8 \%$ overall decrease in the odds of LGA per decade (OR $=0.92,95 \% \mathrm{CI}$ : $0.90,0.94)$.
The supplementary figure (Additional file 4: Fig. S3) shows that the crude rates of LGA exhibited an increase in the total Aboriginal population and a slight decrease in the non-Aboriginal population over the study period.

\section{Discussion}

\section{Trends of pre-gestational diabetes}

In this study, the annual age-standardised and crude rates of PGDM grew considerably (to 5.4 and 3.8\%, respectively) in the last two decades among Aboriginal mothers but remained below $1 \%$ in non-Aboriginal mothers. This is consistent with the extant evidence-base-which confirms the relatively heavy burden of PGDM in Indigenous populations at national $[5,22,23]$ and global [2426] levels - with the highest prevalence rates of PGDM reported among Aboriginal mothers in Central Australia (8.4\%) [6], while PGDM complicated $6.3 \%$ of pregnancies among Arizona's Pima population in the United States [27].

The higher prevalence of PGDM in Indigenous populations is a reflection of the elevated rates (and contrasting demographic characteristics) of T2DM [28]. T2DM accounts for more than $95 \%$ of PGDM cases among 


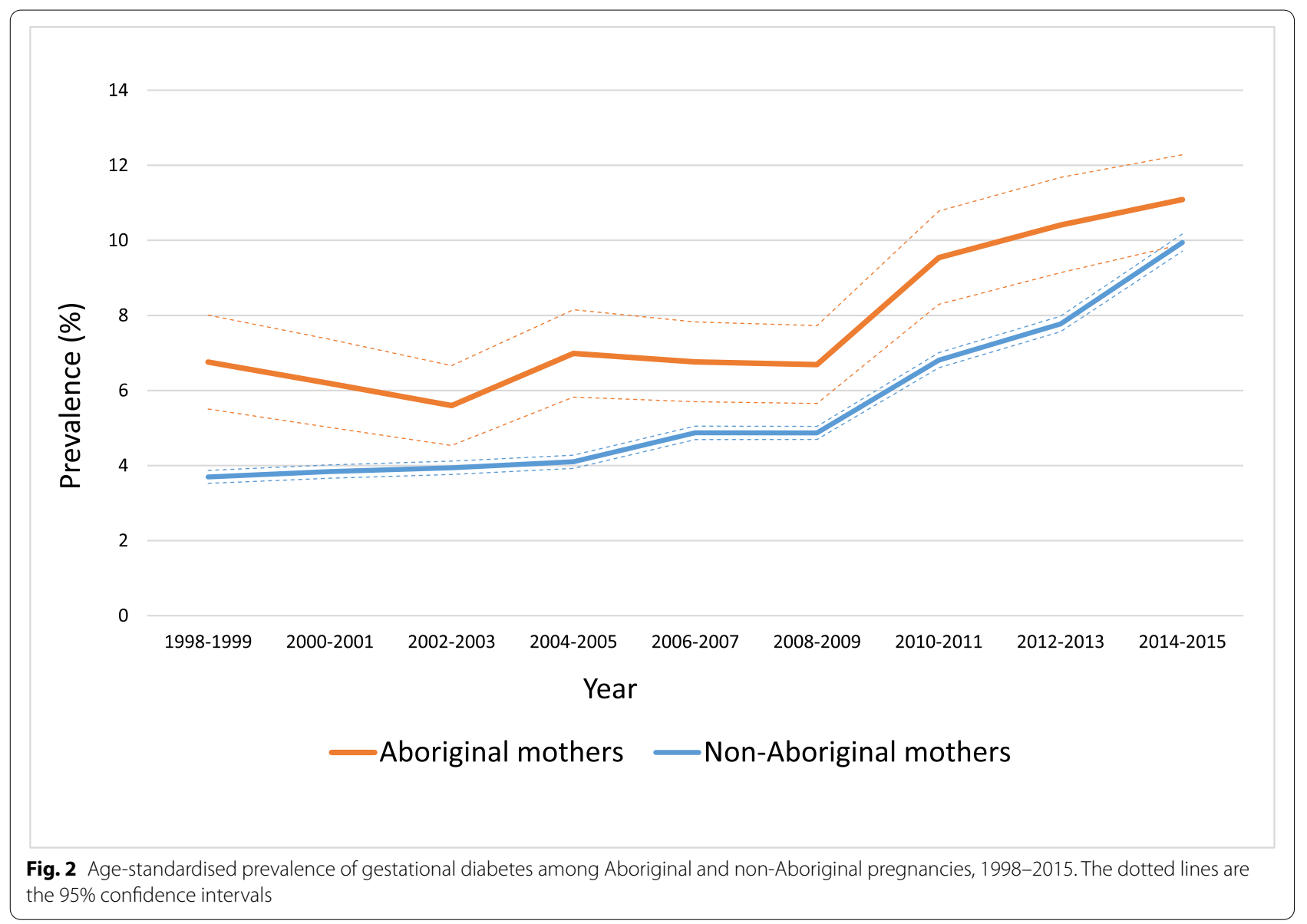

Table 3 Mixed-effects logistic regression for the association between LGA and time (per decade), stratified by Aboriginal status

\begin{tabular}{|c|c|c|c|c|}
\hline & \multirow[t]{2}{*}{ Initial Model ${ }^{a}$} & \multicolumn{3}{|l|}{ Added to Initial Model } \\
\hline & & Gestational diabetes & Pre-gestational diabetes & $\begin{array}{l}\text { Both gestational } \\
\text { and pre-gestational } \\
\text { diabetes }\end{array}$ \\
\hline & OR $(95 \% \mathrm{Cl})$ & OR $(95 \% \mathrm{Cl})$ & OR $(95 \% \mathrm{Cl})$ & OR $(95 \% \mathrm{Cl})$ \\
\hline Aboriginal mothers & $1.16(1.04$ to 1.29$)$ & 1.10 (0.99 to 1.23$)$ & 1.14 (1.02 to 1.26$)$ & 1.07 (0.97 to 1.19$)$ \\
\hline Non-Aboriginal mothers & 0.94 (0.92 to 0.97$)$ & 0.93 (0.91 to 0.95$)$ & 0.94 (0.91 to 0.96$)$ & 0.92 (0.90 to 0.94$)$ \\
\hline
\end{tabular}

C Confidence intervals, LGA large for gestational age, OR Odds ratio

${ }^{a}$ Adjusted for maternal age, parity, remoteness and smoking

Australian Aboriginal mothers compared to approximately 55\% in non-Aboriginal women [6, 29]. In 2015, the prevalence of T2DM (which is preventable) in pregnancy was approximately eight times higher in Western Australian Aboriginal mothers compared with their nonAboriginal counterparts [29]. Disproportionately higher rates of T2DM in Aboriginal youth [30, 31] and the differentially higher incidence of T2DM among Aboriginal females [32, 33] contribute to the disparate burden of PGDM in this population.

Our observation of steeper increasing trends in Indigenous populations (relative to their respective general populations) is a feature of the global health disparities literature [34]. Hare et al., for example, recently reported a ten-fold increase in PGDM among Aboriginal mothers over 30 years in Australia's Northern Territory, with 
a crude prevalence of $5.7 \%$ in 2016 [6]. They found that PGDM rates remained $\leq 0.7 \%$ through the study period in non-Aboriginal mothers. The reasons for the sharp growth in the burden of T2DM among Indigenous populations are complex and multifaceted-although at least in part reflect the rapid behavioural and environmental changes towards urban, sedentary lifestyle and energydense diets $[13,14]$ and the concomitant longer-term legacies of colonisation that have given rise to social and economic circumstances that shape the affordability and accessibility of nutritious foods, healthcare and other proximal determinants of chronic diseases. The steeper increase in PGDM in the Northern Territory study compared to ours may reflect demographic circumstances, whereby a larger proportion of Aboriginal people in the Northern Territory live in remote areas [35] where a change in lifestyle may be more impactful on life outcomes.

\section{Trends of gestational diabetes}

Our results showed that the annual age-standardised rates of GDM increased consistently in Aboriginal mothers and remained higher than that reported in their nonAboriginal counterparts over the two decades to 2015. Annual crude rates of GDM were comparable in Aboriginal and non-Aboriginal mothers. The discrepancies in age structure between Aboriginal and non-Aboriginal mothers, and the established link between the risk of GDM and maternal age [36] indicate that age-standardised rates offer a more meaningful comparison. Crude rates underestimate the disparities between the two populations.

There is a worldwide increasing trends in the prevalence of GDM [37-39] that is believed to be explained by an increase in maternal obesity and older maternal age at birth [40, 41]. Temporal increases in GDM have also been reported in Australian Aboriginal mothers [42]. The crude prevalence increased from 3.4 to $13 \%$ between 1987 and 2016 in the Northern Territory of Australia [6]. There has been evidence from population-level studies of both increasing and stable rates of GDM in Canadian First Nations mothers [34, 43].

Interpreting prevalence trends of GDM is not straightforward and should be considered in conjunction with the temporal changes in screening policies and diagnostic criteria. In 2013, the Australasian Diabetes in Pregnancy Society (ADIPS) adopted the 2010 recommendations of the International Association of Diabetes and Pregnancy Study Groups (Additional file 5: Table S2) [44]. The implementation of the new guidelines was associated with a substantial increase in the prevalence of GDM globally [45], and we expect a similar contribution to the increasing trends of GDM among both Aboriginal and
non-Aboriginal pregnant women in Western Australia. Moreover, between and within jurisdiction discrepancies in the application of diagnostic and screening guidelines [46] may invalidate direct comparisons.

A retrospective audit in rural Western Australia has recently reported inadequate screening for GDM, especially among Aboriginal mothers [47]. Limitations related to the storage of blood samples prior to testing for GDM were also reported in rural and remote Western Australia [48]. Thus, our findings may have underestimated the real prevalence of GDM among the Aboriginal population who are more likely to reside and receive ante-natal care in these areas [29].

\section{Diabetes in pregnancy and LGA over time}

The present study reported that DIP may explain a large part of the increasing trend in LGA among the Aboriginal population. Statistically accounting for PGDM and GDM (separately and collectively) attenuated the LGA increase per decade. Similar results were recently reported among the Aboriginal people of Australia's Northern Territory, but with a stronger impact of PGDM on LGA trends compared to ours, reflecting a sharper rise of PGDM rates among that Aboriginal population over time in the Northern Territory [6].

In line with the impact of DIP on the overall LGA trends among the Aboriginal population, absolute rates of LGA remained high in Aboriginal babies born to mothers with DIP. LGA continued to affect about onethird of Aboriginal births complicated by PGDM, with no signs of improvement over the study period. Despite the improving trends, LGA continued to impact more than $20 \%$ of Aboriginal births complicated by GDM.

\section{Diabetes in pregnancy, LGA and intergenerational diabetes} The association between exposure to intrauterine hyperglycemia and elevated risk for future diabetes in offspring was reported in Indigenous populations in North America [49-52]. Among Canadian Indigenous women, being born HBW was associated with differentially increased risk of T2DM and GDM, and is believed to play a role in the intergenerational transfer of diabetes risk $[9,53]$. Although the present study did not investigate the intergenerational effect of DIP, our findings regarding the over time burden of DIP and its associated LGA are probably in-line with the DIP-driven intergenerational cycle of diabetes in Indigenous populations.

\section{Health risks may add to burden of diabetes in pregnancy} We reported smoking rates of approximately 40-50\% among Aboriginal mothers with GDM and PGDM, with 
no improvement over the study period. Maternal exposure to tobacco smoke during pregnancy significantly increases the risk of T2DM [54, 55], obesity [56] and GDM [57] in offspring. Epigenetic modifications are believed to mediate these effects [58]. The sizeable rates of maternal smoking may thus add to the intergenerational impact of DIP in the Aboriginal population. Likewise, low birth weight may synergistically interact with genetic susceptibility to obesity to heighten the future risk of T2DM [59]. Given the substantially higher prevalence of many health risks in Aboriginal Australians [60], it is plausible that there may be similar interactions between DIP and health risk behaviours with potential intergenerational implications.

\section{Positive findings}

The present study also reported some positive findings. The rates of pre-eclampsia decreased in Aboriginal mothers with GDM and PGDM, and LGA decreased in Aboriginal pregnancies complicated by GDM. These positive trends can probably be attributed to improved antenatal care [61], increasing awareness about GDM following the Hyperglycemia and Adverse Pregnancy Outcomes study $[62,63]$, increased screening rates and the introduction of new diagnostic criteria [44]. These factors might have resulted in better glycemic control and capturing of the less severe cases of GDM.

\section{Strengths and limitations of the study}

The use of linked, population-level datasets from multiple sources is a strength of the present study. This eliminates selection bias; allows tracking of babies and mothers upon transfer between different levels of health facilities; and maximises the external validity of the study. Utilizing multiple sources of data also increases the sensitivity of capturing medical conditions by enabling the identification of additional cases. Further, we have used a robust, agreed algorithm for the identification of Aboriginal people in the study data sources [16]. This has been shown to reduce missing data and improve within-individual consistency across time, and is likely to have minimised any potential for under-estimation of increasing DIP trends.

Our study does, however, have some limitations. We used routinely collected data that are not originally designed for research purposes. The capture of DIP over time in the HMDC is impacted by changes in the Australian diabetes coding standards that implies modifications to the documentation of diabetes during a hospital admission [64]. However, we believe that using both MNS and HMDC has improved the capture of DIP. Absence of data on maternal weight is also a limitation of this study.
Obesity, which is increasing over time in Australia [65], is linked to both DIP and HBW and can be a source of unmeasured temporal confounding that may explain part of the relationship between DIP and LGA [6]. Moreover, we did not have data on glycemic control biomarkers. Hyperglycemia during pregnancy is an established risk factor for adverse fetal outcomes, and its trends might have explained part of the trend in these outcomes.

\section{Conclusions}

Our whole-population study reported a disproportionately growing burden of PGDM and increasing rates of GDM among Aboriginal mothers in Western Australia between 1998 and 2015. DIP appears to explain a high proportion of the increase in LGA trends in the Aboriginal population.

The fact that T2DM, which can be preventable, is behind the vast majority of PGDM cases among the Aboriginal mothers highlights the need for appropriate primary prevention strategies. Increasing GDM trends despite inadequate screening among Aboriginal women points to both the substantial, possibly hidden, size of the problem, the need for improving prenatal care and, concomitantly, the potential for interrupting the impact of the cycle of intergenerational diabetes among the Aboriginal population.

\section{Abbreviations}

Cl: Confidence interval; DIP: Diabetes in pregnancy; GDM: Gestational diabetes mellitus; HBW: High birth weight; HMDC: Hospital Morbidity Database Collection; LGA: Large for gestational age; MNS: Midwives Notification System; OR: Odds ratio; PGDM: Pre-gestational diabetes mellitus; T2DM:Type 2 diabetes mellitus.

\section{Supplementary Information}

The online version contains supplementary material available at https://doi. org/10.1186/s12889-022-12663-6.

Additional file 1: Table S1. Maternal and neonatal characteristics of Aboriginal and non-Aboriginal singleton pregnancies in Western Australia, 1998-2015.

Additional file 2: Figure S1. Crude prevalence of pre-gestational diabetes among Aboriginal and non-Aboriginal pregnancies, 1998-2015.

Additional file 3: Figure S2. Crude prevalence of gestational diabetes among Aboriginal and non-Aboriginal pregnancies, 1998-2015.

Additional file 4: Figure S3. Rates of LGA over time in the Aboriginal and non-Aboriginal populations in Western Australia, 1998-2015.

Additional file 5: Table S2. National guidelines for screening and diagnosis of gestational diabetes during the study period (1998-2015).

\section{Acknowledgements}

The authors would like to thank the Data Linkage Branch of the Western Australia Government Department of Health and the data custodians of the MNS, Birth and Death Registries and HMDC for providing data for this project. We also gratefully acknowledge the contribution of Kaadaninny Aboriginal Reference Group. 


\begin{abstract}
Authors' contributions
MAA designed the study, analysed the data, interpreted the results and drafted the manuscript. CCJS and HDB co-designed the study, interpreted the results, contributed to data analysis and critically revised the manuscript. GP and KW contributed to data analysis and substantively revised the manuscript. SWW contributed to the study design and substantively revised the manuscript. All authors have revised and approved the final version of manuscript.
\end{abstract}

\section{Funding}

MAA is supported by an Australian Government Research Training Program (RTP) Scholarship, a University Postgraduate Award from the University of Western Australia and the Peter and Anne Hector Award. HDB and CCJS are supported by a National Health and Medical Research Council grant (APP 1127265). GP is supported with funding from the National Health and Medical Research Council Project and Investigator Grants \#1099655 and \#1173991, institutional funding for the WA Health and Artificial Intelligence Consortium, and the Research Council of Norway through its Centres of Excellence funding scheme \#262700. These funders had no involvement in the design of the study, data analysis and interpretation or in writing the manuscript.

\section{Availability of data and materials}

Datasets used in this study are not publicly available and cannot be provided by authors due to restrictions by the data custodians. Researchers wanting to access these datasets should refer to the Data Linkage Branch of the Western Australia Government Department of Health (www.datalinkage-wa.org.au).

\section{Declarations}

\section{Ethics approval and consent to participate}

Ethics approvals for this study were obtained from the Western Australian DoH Human Research Ethics Committee (RGS0000003168), Western Australian Aboriginal Health Ethics Committee (Project 797) and University of Western Australia Human Research Ethics Committee (RA/4/20/6161). Informed consent was waived by the Western Australian DoH Human Research Ethics Committee (RGS0000003168), Western Australian Aboriginal Health Ethics Committee (Project 797) and University of Western Australia Human Research Ethics Committee (RA/4/20/6161). A waiver of informed consent was supported by these ethics committees because the study: (1) retrospectively uses existing, routinely collected, administrative datasets (no active participants); and (2) utilizes de-identified data with their storage, analysis and dissemination subject to strict protocols. Individual informed consent was thus not obtained from the participants, but consent was given from the data custodians on their behalf. This study was conducted in accordance with the ethical standards of the Declaration of Helsinki (1964) and its subsequent amendments.

\section{Consent for publication}

Not applicable.

\section{Competing interests}

The authors declare that they have no competing interests.

\begin{abstract}
Author details
${ }^{1}$ Telethon Kids Institute, University of Western Australia, P.O. Box 855, West Perth, Western Australia 6872, Australia. ${ }^{2}$ School of Population and Global Health, The University of Western Australia, Perth, Australia. ${ }^{3}$ Curtin School of Population Health, Curtin University, Perth, Western Australia, Australia. ${ }^{4}$ Centre for Fertility and Health (CeFH), Norwegian Institute of Public Health, Oslo, Norway. ${ }^{5}$ Division of Obstetrics and Gynaecology, The University of Western Australia, Perth, WA, Australia. ${ }^{6}$ Maternal Fetal Medicine Service, King Edward Memorial Hospital, Subiaco, WA, Australia. ${ }^{7}$ Curtin Medical School, Faculty of Health Sciences, Curtin University, Perth, Australia. ${ }^{8}$ Ngangk Yira Research Centre, Murdoch University, Perth, WA, Australia.
\end{abstract}

Received: 30 May 2021 Accepted: 21 January 2022

Published online: 09 February 2022

\section{References}

1. Mitanchez D, Yzydorczyk C, Siddeek B, Boubred F, Benahmed M, Simeoni $U$. The offspring of the diabetic mother--short- and long-term implications. Best Pract Res Clin Obstet Gynaecol. 2015;29(2):256-69.

2. Clausen TD, Mathiesen ER, Hansen T, Pedersen O, Jensen DM, Lauenborg $J$, et al. High prevalence of type 2 diabetes and pre-diabetes in adult offspring of women with gestational diabetes mellitus or type 1 diabetes: the role of intrauterine hyperglycemia. Diabetes Care. 2008;31(2):340-6.

3. Knop MR, Geng TT, Gorny AW, Ding R, Li C, Ley SH, et al. Birth weight and risk of type 2 diabetes mellitus, cardiovascular disease, and hypertension in adults: a Meta-analysis of 7646267 participants from 135 studies. J Am Heart Assoc. 2018;7(23):e008870.

4. Voaklander B, Rowe S, Sanni O, Campbell S, Eurich D, Ospina MB. Prevalence of diabetes in pregnancy among indigenous women in Australia, Canada, New Zealand, and the USA: a systematic review and meta-analysis. Lancet Glob Health. 2020;8(5):e681-e98.

5. Australian Institute of Health Welfare. Diabetes in pregnancy: its impact on Australian women and their babies. Canberra: AlHW; 2010.

6. Hare MJ, Barzi F, Boyle JA, Guthridge S, Dyck RF, Barr EL, et al. Diabetes during pregnancy and birthweight trends among Aboriginal and nonAboriginal people in the Northern Territory of Australia over 30 years. Lancet Region Health Western Pac. 2020;1:100005.

7. Australian Institute of Health Welfare. Diabetes in pregnancy 2014-2015. Canberra: AlHW; 2019.

8. Osgood ND, Dyck RF, Grassmann WK. The inter- and intragenerational impact of gestational diabetes on the epidemic of type 2 diabetes. Am J Public Health. 2011;101(1):173-9.

9. Dyck RF, Karunanayake C, Pahwa P, Osgood ND. The hefty fetal phenotype hypothesis revisited: high birth weight, type 2 diabetes and gestational diabetes in a Saskatchewan cohort of first nations and non-first nations women. J Dev Orig Health Dis. 2019;10(1):48-54.

10. Lavery JA, Friedman AM, Keyes KM, Wright JD, Ananth CV. Gestational diabetes in the United States: temporal changes in prevalence rates between 1979 and 2010. BJOG. 2017;124(5):804-13.

11. Feig DS, Hwee J, Shah BR, Booth GL, Bierman AS, Lipscombe LL. Trends in incidence of diabetes in pregnancy and serious perinatal outcomes: a large, population-based study in Ontario, Canada, 1996-2010. Diabetes Care. 2014;37(6):1590-6.

12. Coton SJ, Nazareth I, Petersen I. A cohort study of trends in the prevalence of pregestational diabetes in pregnancy recorded in UK general practice between 1995 and 2012. BMJ Open. 2016;6(1):e009494.

13. Guest CS, O'Dea K. Diabetes in aborigines and other Australian populations. Aust J Public Health. 1992;16(4):340-9.

14. O'dea K. Westernization and non-insulin-dependent diabetes in Australian aborigines. Ethn Dis. 1991;1(2):171-87.

15. Holman CD, Bass AJ, Rouse IL, Hobbs MS. Population-based linkage of health records in Western Australia: development of a health services research linked database. Aust N Z J Public Health. 1999;23(5):453-9.

16. Christensen D. Evidence for the use of an algorithm in resolving inconsistent and missing indigenous status in administrative data collections. Austr J Soc Issues. 2014;49(4):423-43.

17. Dobbins TA, Sullivan EA, Roberts CL, Simpson JM. Australian national birthweight percentiles by sex and gestational age, 1998-2007. Med J Aust. 2012;197(5):291-4.

18. Commonwealth Department of Health and Aged Care. Measuring remoteness: Accessibility/Remoteness Index of Australia (ARIA) [updated 2001. revised edition: Available from: https://www1.health.gov.au/inter net/main/publishing.nsf/Content/health-historicpubs-hfsocc-ocpan ew14a.htm.

19. Pink B. Technical paper: socio-economic indexes for areas (SEIFA). Canberra: Australian Bureau of Statistics; 2013.

20. Royston P. PTREND: Stata module for trend analysis for proportions; 2014

21. Australian Institute of Health Welfare. A guide to statistical methods for injury surveillance. Canberra: AlHW; 2005.

22. Sharpe PB, Chan A, Haan EA, Hiller JE. Maternal diabetes and congenital anomalies in South Australia 1986-2000: a population-based cohort study. Birth Defects Res A Clin Mol Teratol. 2005;73(9):605-11. 
23. Kirkham R, Whitbread C, Connors C, Moore E, Boyle JA, Richa R, et al. Implementation of a diabetes in pregnancy clinical register in a complex setting: findings from a process evaluation. PLoS One. 2017;12(8):e0179487.

24. Shen GX, Shafer LA, Martens PJ, Sellers E, Torshizi AA, Ludwig S, et al. Does first nations ancestry modify the association between gestational diabetes and subsequent diabetes: a historical prospective cohort study among women in Manitoba, Canada. Diabet Med. 2016;33(9):1245-52.

25. Anderson KG, Spicer P, Peercy MT. Obesity, diabetes, and birth outcomes among American Indians and Alaska natives. Matern Child Health J. 2016;20(12):2548-56.

26. Chen L, Wang WJ, Auger N, Xiao L, Torrie J, McHugh NG, et al. Diabetes in pregnancy in associations with perinatal and postneonatal mortality in first nations and non-indigenous populations in Quebec, Canada: population-based linked birth cohort study. BMJ Open. 2019;9(4):e025084.

27. Pettitt DJ, Knowler WC, Baird HR, Bennett PH. Gestational diabetes: infant and maternal complications of pregnancy in relation to third-trimester glucose tolerance in the Pima Indians. Diabetes Care. 1980;3(3):458-64.

28. Dyck R, Osgood N, Lin TH, Gao A, Stang MR. Epidemiology of diabetes mellitus among first nations and non-first nations adults. CMAJ. 2010;182(3):249-56

29. Hutchinson M, Joyce A, Peirce A. Western Australia's mothers and babies, 2015: 33rd annual report of the Western Australian midwives' notification system. Western Australia: Department of Health; 2019.

30. Haynes A, Kalic R, Cooper M, Hewitt JK, Davis EA. Increasing incidence of type 2 diabetes in indigenous and non-indigenous children in Western Australia, 1990-2012. Med J Aust. 2016;204(8):303.

31. Craig ME, Femia G, Broyda V, Lloyd M, Howard NJ. Type 2 diabetes in indigenous and non-indigenous children and adolescents in New South Wales. Med J Aust. 2007;186(10):497-9.

32. Wang Z, Hoy WE, Si D. Incidence of type 2 diabetes in Aboriginal Australians: an 11-year prospective cohort study. BMC Public Health. 2010;10(1):487.

33. Minges KE, Zimmet P, Magliano DJ, Dunstan DW, Brown A, Shaw JE. Diabetes prevalence and determinants in indigenous Australian populations: a systematic review. Diabetes Res Clin Pract. 2011;93(2):139-49.

34. Dyck RF, Karunanayake C, Pahwa P, Stang M, Osgood ND. Epidemiology of diabetes in pregnancy among first nations and non-first nations women in Saskatchewan, 1980-2013. Part 2: predictors and early complications; results from the DIP: ORRIIIGENSS project. Can J Diabetes. 2020;44(7):605-14.

35. Australian Bureau of Statistics. Estimates of Aboriginal and Torres Strait Islander Australians, June 2016. Canberra: ABS; 2018. Report No.: cat. no. 3238.0.55.001.

36. Li Y, Ren X, He L, Li J, Zhang S, Chen W. Maternal age and the risk of gestational diabetes mellitus: a systematic review and meta-analysis of over 120 million participants. Diabetes Res Clin Pract. 2020;162:108044.

37. Zhu Y, Zhang C. Prevalence of gestational diabetes and risk of progression to type 2 diabetes: a global perspective. Curr Diab Rep. 2016;16(1):7.

38. Lavery JA, Friedman AM, Keyes KM, Wright JD, Ananth CV. Gestational diabetes in the United States: temporal changes in prevalence rates between 1979 and 2010. BJOG Int J Obstet Gynaecol. 2017;124(5):804-13.

39. Ferrara A. Increasing prevalence of gestational diabetes mellitus: a public health perspective. Diabetes Care. 2007;30(Supplement 2):S141-S6.

40. Kampmann U, Madsen LR, Skajaa GO, Iversen DS, Moeller N, Ovesen P. Gestational diabetes: a clinical update. World J Diabetes. 2015;6(8):1065.

41. Benhalima K, Damm P, Van Assche A, Mathieu C, Devlieger R, Mahmood T, et al. Screening for gestational diabetes in Europe: where do we stand and how to move forward?: a scientific paper commissioned by the European Board \& College of obstetrics and Gynaecology (EBCOG). Eur J Obstet Gynecol Reprod Biol. 2016;201:192-6.

42. Chamberlain C, Banks E, Joshy G, Diouf I, Oats JJ, Gubhaju L, et al. Prevalence of gestational diabetes mellitus among indigenous women and comparison with non-indigenous Australian women: 1990-2009. Aust N Z J Obstet Gynaecol. 2014;54(5):433-40.

43. Oster RT, King M, Morrish DW, Mayan MJ, Toth EL. Diabetes in pregnancy among first nations women in Alberta, Canada: a retrospective analysis. BMC Pregnancy Childbirth. 2014;14(1):136.

44. Nankervis A, MH MR. Australasian Diabetes in Pregnancy Society (ADIPS). ADIPS consensus guidelines for the testing anddiagnosis of gestational diabetes mellitus in Australia Available online from: http://www.adips.
org/downloads/ADIPSConsensusGuidelinesGDM-0305.13VersionACCEPT EDFINAL.pdf. 2013.

45. Behboudi-Gandevani S, Amiri M, Bidhendi Yarandi R, Ramezani TF. The impact of diagnostic criteria for gestational diabetes on its prevalence: a systematic review and meta-analysis. Diabetol Metab Syndr. 2019;11:11.

46. Rumbold AR, Crowther CA. Guideline use for gestational diabetes mellitus and current screening, diagnostic and management practices in Australian hospitals. Aust N Z J Obstet Gynaecol. 2001;41(1):86-90.

47. Kirke AB, Atkinson D, Moore S, Sterry K, Singleton S, Roxburgh C, et al. Diabetes screening in pregnancy failing women in rural Western Australia: an audit of oral glucose tolerance test completion rates. Aust J Rural Health. 2019;27(1):64-9.

48. Jamieson EL, Spry EP, Kirke AB, Atkinson DN, Marley JV. Real-world gestational diabetes screening: problems with the Oral glucose tolerance test in rural and remote Australia. Int J Environ Res Public Health. 2019;16(22):4488.

49. Dabelea D, Hanson RL, Lindsay RS, Pettitt DJ, Imperatore G, Gabir MM, et al. Intrauterine exposure to diabetes conveys risks for type 2 diabetes and obesity: a study of discordant sibships. Diabetes. 2000;49(12):2208-11.

50. Young TK, Martens PJ, Taback SP, Sellers EA, Dean HJ, Cheang M, et al. Type 2 diabetes mellitus in children: prenatal and early infancy risk factors among native Canadians. Arch Pediatr Adolesc Med. 2002;156(7):651-5.

51. Wicklow BA, Sellers EA, Sharma AK, Kroeker K, Nickel NC, Philips-BeckW, et al. Association of gestational diabetes and type 2 diabetes exposure in utero with the development of type 2 diabetes in first nations and nonfirst nations offspring. JAMA Pediatr. 2018;172(8):724-31.

52. Sellers EA, Dean HJ, Shafer LA, Martens PJ, Phillips-Beck W, Heaman M, et al. Exposure to gestational diabetes mellitus: impact on the development of early-onset type 2 diabetes in Canadian first nations and nonfirst nations offspring. Diabetes Care. 2016;39(12):2240-6.

53. Dyck RF, Cascagnette PJ, Klomp H. The importance of older maternal age other birth-related factors as predictors for diabetes in offspring: particular implications for first nations women? Can J Diabetes. 2010;34(1):41-9.

54. Banderali G, Martelli A, Landi M, Moretti F, Betti F, Radaelli G, et al. Short and long term health effects of parental tobacco smoking during pregnancy and lactation: a descriptive review. J Transl Med. 2015;13(1):1-7.

55. La Merrill MA, Cirillo PM, Krigbaum N, Cohn B. The impact of prenatal parental tobacco smoking on risk of diabetes mellitus in middle-aged women. J Dev Orig Health Dis. 2015;6(3):242.

56. Maessen SE, Ahlsson F, Lundgren M, Cutfield WS, Derraik JG. Maternal smoking early in pregnancy is associated with increased risk of short stature and obesity in adult daughters. Sci Rep. 2019;9(1):1-9.

57. Mattsson K, Källén K, Longnecker M, Rignell-Hydbom A, Rylander L. Maternal smoking during pregnancy and daughters' risk of gestational diabetes and obesity. Diabetologia. 2013;56(8):1689-95.

58. Rogers JM. Smoking and pregnancy: epigenetics and developmental origins of the metabolic syndrome. Birth Defects Res. 2019;111(17):1259-69.

59. Li Y, Qi Q, Workalemahu T, Hu FB, Qi L. Birth weight, genetic susceptibility, and adulthood risk of type 2 diabetes. Diabetes Care. 2012;35(12):2479-84.

60. Australian Institute of Health Welfare. Australia's health 2018. Canberra: AlHW; 2018.

61. Australian Institute of Health Welfare. Australia's mothers and babies. Canberra: AlHW; 2021.

62. Coustan DR, Lowe LP, Metzger BE, Dyer AR. International Association of D, pregnancy study $\mathrm{G}$. the hyperglycemia and adverse pregnancy outcome (HAPO) study: paving the way for new diagnostic criteria for gestational diabetes mellitus. Am J Obstet Gynecol. 2010;202(6):654 e1-6.

63. International Association of Diabetes, Pregnancy Study Groups Consensus Panel, Metzger BE, Gabbe SG, Persson B, Buchanan TA, et al. International association of diabetes and pregnancy study groups recommendations on the diagnosis and classification of hyperglycemia in pregnancy. Diabetes Care. 2010;33(3):676-82.

64. Australian Institute of Health Welfare. Improving national reporting on diabetes in pregnancy: technical report. Canberra: AlHW; 2019.

65. Australian Institute of Health Welfare. Overweight and obesity: an interactive insight. Canberra: AlHW; 2020.

\section{Publisher's Note}

Springer Nature remains neutral with regard to jurisdictional claims in published maps and institutional affiliations. 